\title{
Emergency remote education in Bahrain, Iraq, and Russia During the COVID-19 pandemic: A comparative case study
}

\author{
Christine Elizabeth (Noor) Coutts ${ }^{\mathrm{a}, *}$, Mohamed Buheji $^{\mathrm{b}}$, Dunya Ahmed ${ }^{\mathrm{b}, \mathrm{c}}$, Talal Abdulkareem ${ }^{\mathrm{d}}$, \\ Budhoor Buheji $^{\mathrm{e}}$, Sajeda Eidan ${ }^{\mathrm{d}}$ and Nikolay Perepelkin ${ }^{\mathrm{f}}$ \\ ${ }^{a}$ Quality House Consultancy, Bahrain \\ ${ }^{\mathrm{b}}$ International Institute of Inspiration Economy, Bahrain \\ ${ }^{\mathrm{c}}$ University of Bahrain, Bahrain \\ ${ }^{\mathrm{d}}$ University of Baghdad, Baghdad, Iraq \\ ${ }^{\mathrm{e}}$ Gifted Students Centre, Bahrain \\ ${ }^{\mathrm{f}}$ Plekhanov Russian University of Economics, Russia
}

Received 7 September 2020

Accepted 12 October 2020

\begin{abstract}
.
BACKGROUND: During the COVID-19 pandemic many education organizations closed their doors to contain the spread of infection, providing learning continuity by distance and online delivery.

OBJECTIVE: To explore the challenges educators faced during emergency remote learning so that others may learn from their experience.

METHOD: A case study based on the experience of educators compares how education continuity was provided in Bahrain, Iraq, and Russia. Personal insights gathered using Zoom, complemented by documentary evidence, explore the 'lived experience' of the emergency changes made to teaching and learning provision.

RESULTS: Whilst teachers and students were ill-prepared, and there were issues with electricity supply, stable Wi-Fi, and access to equipment, most countries were able to offer students access to learning using a combination of distance education and online learning. Benefits accrued were greater familiarity with the use of technology and a revaluing of the importance of social relations in teaching and learning. Early indications are that educational inequities may have been widened as a consequence.

CONCLUSION: The challenges facing the education sector fall into three main categories: crisis management and decision making, infrastructure readiness, and student receptiveness. A hybrid approach, which blends face-to-face with online learning, is the way forward in the 'new normal' post-pandemic.
\end{abstract}

Keywords: Global, emergency remote education, COVID-19 pandemic, teaching and learning, online education, hybridlearning

${ }^{*}$ Corresponding author: Christine Elizabeth (Noor) Coutts, Quality House Consultancy, Bahrain. E-mail: Chris-coutts@ hotmail.com.

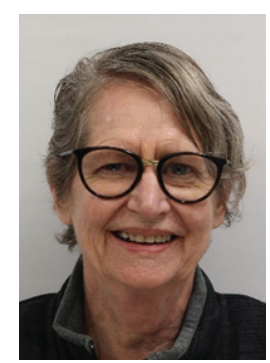

Dr. Noor (Chris) Coutts is an international education consultant with Quality House Consultancy (Bahrain). Noor's quality improvement plans have provided industry sustainability in an increasingly competitive and complex marketplace. Noor was Academic Advisor on the team that established Bahrain Polytechnic. Previously she was a Secondary School Principal and Polytechnic Director in New Zealand. She is an experienced 
quality auditor currently working in GCC on school and vocational education improvement projects. Research interests include sustainability, employability, entrepreneurship, drop-out, and problem-based learning. https://www.qhc-bh.com

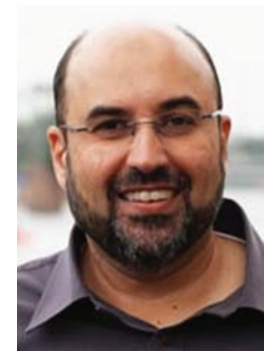

Dr. Mohamed Buheji is project lead for 'COVID-19 Untapped Solutions', a subsidiary of International Inspiration Economy Projects (IIEP). IIEP focuses on three concepts relevant to COVID-19 pandemic spillovers: inspiration-, youth- and resilienceeconomy. Dr. Buheji is passionate about multi-disciplinary approaches for complex problem solving, working on the enhancement of competitiveness; future foresight; socioeconomic problem-solving; the power of thinking; lifelong learning; curiosity, and poverty. Recently retired from a professorship at the University of Bahrain, Dr. Buheji is Founder of the International Journal of Inspiration and Resilience Economy and International Journal of Youth Economy, authoring 29 books and 200 publications: https://www.researchgate.net/profile/Mohamed_Buheji

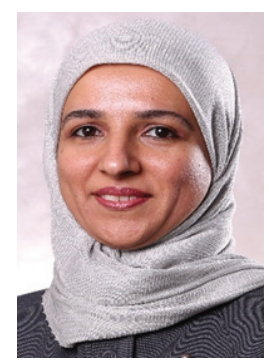

Dr. Dunya Ahmed is an Assistant Professor at the University of Bahrain. She is chairperson of Inspiration Economy Society (Bahrain) and the Scientific Committee of the Institute of Inspiration Economy (EU \& MENA). After completing her Ph.D. in social work at Warwick University, she now specializes in equity issues, women's rights and empowerment, and entitlements for people of determination. She is cofounder of the Inspiration Economy concept, contributing actively to its journal and projects globally. She is an active member of several NGOs. An active researcher, she is on several editorial boards and regularly publishes journal articles, reports, and conference papers. https://www.researchgate.net/profile/Mohamed_Buheji/ publications

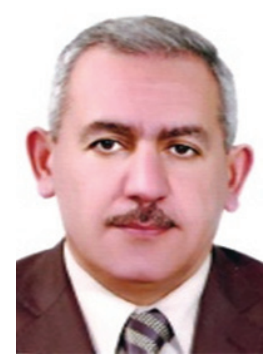

Dr. Talal Anwer Abdulkareem is a Professor of Reproductive Physiology in the Department of Animal Production, College of Agricultural Engineering Sciences, University of Baghdad. A Fulbright Scholar in 2010, he was trained in agriculture, public health, and economics. He currently advises Iraq's Ministry of Agriculture on projects involving artificial insemination and embryo transfer for cattle. A well-published author of international repute, he has written $80+$ articles, seven books, and two collaborative chapters. He contributes to the international academic community through peer reviews, membership of editorial boards, and supervision of post-graduate students. He is actively involved in committees improving Iraq's higher education.

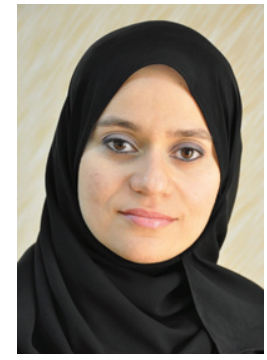

Dr. Budoor Mohammed Buheji heads Bahrain's Ministry of Education Gifted Student Center, having worked in the field of gifted education and special needs provision since 2007. A well-qualified, and highly experienced specialist, she holds both masters and doctoral qualifications awarded by Arabian Gulf University and is certified by the International Academy for Training and Consulting (IATC) as a trainer. Dr. Buheji is a highly regarded author, with five lished locally and in international journals. books and many research articles pub-

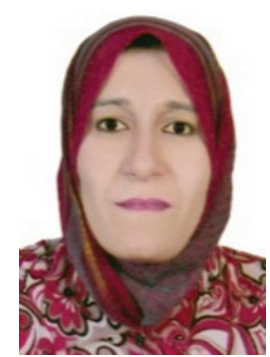

Dr. Sajeda M. Eidan is a Professor of Reproductive Physiology in the Department of Animal Production, College of Agricultural Engineering Sciences at the University of Baghdad. She has published in Iraq and internationally, contributing $50+$ articles, six books, and two collaborative chapters. Currently, technical editor of Theriogenology Insight journal, she supervises postgraduate students in the field of reproductive physiology and semen cryopreservation. She also consults for Iraq's Ministry of Agriculture in projects involving artificial insemination and embryo transfer in cattle.

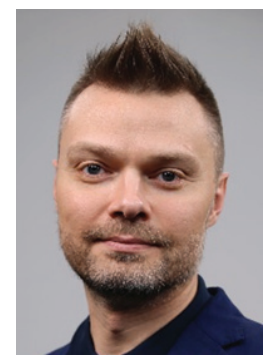

Dr. Nikolay A. Perepelkin is an Associate Professor within the marketing department at the Plekhanov Russian University of Economics, guest lecturer for the Graduate School of Management (SPbU, Russia), Russian Presidential Academy of National Economy and Public Administration (RANEPA, Moscow), and tutor at The Chartered Institute of Marketing (London). He is the owner and senior partner of YES - 'Your Event Solutions', a company specializing in event marketing, marketing communications, and public relations management. Nikolay is an editorial board member for the International Journal of Youth Economy.

\section{Introduction}

\subsection{Preamble}

On March 11, 2020, the World Health Organization (WHO) declared a global pandemic in response to the accelerating spread of a coronavirus, COVID-19, citing 118,000 confirmed cases across 114 countries, 4,291 deaths, and thousands of people hospitalized [1]. Most countries mandated education 'lockdowns,' closing schools and universities to contain community spread of infection. The World Bank estimates 
1.5 billion children and youth are impacted [2], arguing that extended closures result in loss of learning in the short-term but also diminished human capital that will affect economic opportunities over the long-term.

Faced with this crisis, most institutions attempted to maintain provision using alternative learning modes. Many leading universities had already invested in various types of distance and e-learning, so simply extended these services during lockdowns. This was not the case across all tertiary institutions, nor in most schools, where what has been termed "emergency remote learning" [3] was implemented. This case study explores the challenges that faced educators from diverse education systems in Bahrain, Iraq, and Russia during the pandemic. Themes emerging from this comparative case study will be discussed in the context of pre-pandemic global trends to identify issues requiring consideration in future education planning. Given high levels of economic uncertainty, a particular emphasis will be on enabling the education sector to better prepare young people for the post-COVID workplace.

\subsection{Rationale}

Given the high probability of further epidemics caused by new mutations and periodic re-infestations, the International Institute of Inspiration Economy (IIIE) Self-Sufficiency Network reasoned that many of the educational changes implemented in the wake of COVID-19 will continue. During the pandemic, a group of IIIE members involved in delivering emergency remote learning collaborated virtually to develop this case study. By sharing their 'lived' experiences, educators in Bahrain, Iraq, and Russia provide a clear path towards a more inclusive and quality education moving forward, where quality is seen as 'fit-for-purpose' and linked with parallel economic and employment changes.

This journey begins by reviewing the literature to illuminate the educational context pre-pandemic.

\section{Literature}

Three key trends that emerged across the education sector last decade were accelerated by the pandemic, necessitating attention in the literature review:

- Technology in education

- Quality and inclusivity

- Employability skills.

\subsection{Technology in education}

The use of technology is transforming whole industries, including the education sector, enabling many modes of learning, along with face-to-face classroom learning.

- Distance Learning: Any method of studying remotely without students physically attending classes including learning online, or via correspondence, television, or radio.

- e-Learning: Learning through electronic media or supported by electronic resources (audio/visual resources such as tapes, CDs, DVDs, films, and PowerPoints), whether in class or remotely.

- m-Learning: A sub-set of e-learning using mobile phones or Tablets without permanent network connections.

- Online Learning: Remote learning using the Web as an intermediary.

- Blended or Hybrid Learning: Combines traditional face-to-face teaching with e-learning.

- Synchronous learning: Teachers and students are online at the same time, allowing for discussions, and presentations.

- Asynchronous classes: Students complete their work at a time and place to suit their schedule.

- Flipped-class: Combines synchronous and asynchronous approaches, with students using class-time for discussions of learning acquired by previous self-study [4].

In the period of emergency remote learning during the COVID-19 pandemic, educators improvised "quick solutions in less-than-ideal circumstances" [3]. Thompson's report of 127 countries [5] indicated that television was the main channel adopted by threequarters of governments to provide learning continuity. Half of the countries were offering take-home printed resources as their main approach, with radio ranked as third most-used. As with television, radio ownership varies widely, with urban children twice as likely as rural counterparts to have access. Television, radio, and printed resources were typically used in developing countries, or remote rural areas, where the internet is not available, or the signal is weak.

Less than half the population has access to the internet, yet three-quarters of governments used online platforms to deliver education. A majority of countries used SMS, mobile, or social media as an alternate delivery mode during the pandemic [5]. Almost all technologies used to deliver education while 
schools were closed require electricity but in seven (mainly African) countries, less than 10 percent of the poorest households have electricity [5]. Such findings suggest that the remote emergency learning provided during the pandemic may be widening inequities between the rich and the poor, between rural and urban. But what was the situation pre-COVID?

\subsection{Inclusive and quality education}

In 2019, the United Nations Development Program (UNDP) reported substantive progress towards universal primary education, with 91 percent of children in developing regions enrolled in school and a "dramatic increase in literacy rates" [6]. But even before COVID-19 broke out in 2020, there was limited progress in regions suffering from poverty and conflict, with 57 million primary-aged children not attending, and rural-urban disparities that affected girls more. School completion rates are low in developing countries, with 103 million youth lacking basic literacy skills ( 60 percent being female).

In a global study of Goal 4 targets for 'inclusive and quality education for all' [7], the United Nations found increased participation in early years learning (from $62 \%$ in 2010 to $67 \%$ in 2018), despite wide variation amongst the 74 participating countries. Primary school completion rates rose from 70 percent in 2000 to 84 percent in 2018 , with an 89 percent school completion rate predicted globally by 2030 . However, given the impact of COVID-19 on education in 2020, is this likely?

This United Nations study also showed a disparity between students from the richest and poorest sectors of the population, with parity achieved by 25 percent of countries for primary and lower secondary education, but by only one percent at upper secondary. Consequently, some 773 million adults, two-thirds of them women, remain illiterate, even though the global adult literacy rate for the population aged 15 years and above, was 86 percent in 2018 . Has the COVID-19 pandemic widened such disparities?

Teacher education is an important factor in educational effectiveness. Data comparing 129 countries showed the percentage of primary school teachers receiving the minimum pedagogical training has stagnated at 85 percent since 2015 , with some countries significantly below [7]. It is unlikely that this minimum training will include the use of technology in teaching and learning. How prepared were teachers for the shift to remote learning during the pandemic?
And what of the students? Symonds' study of both undergraduate and postgraduate students' responses to the coronavirus crisis [8] indicated a general acceptance of online learning as a pragmatic solution for education continuity during lockdowns but reported concerns about safety and welfare, particularly access to sanitizers, medics, a helpline, and classroom protection when classes resume. Prospective students wanted to know about institutional plans for stopping virus infections as much as academic study options.

The pandemic changed students' education pathways [8]. Half reported changed plans, such as canceling or delaying overseas study. Most students (80\%) did not regard online study highly, believing it was easier to administer, and therefore should be cheaper. A high proportion (40\%) refused to study online, with only 10 percent considering studying remotely towards qualifications offered by a foreign university. These students may be atypical, but their apparent reluctance to embrace online learning raises questions about how the education sector can best prepare them for an uncertain future, especially given that a core element in the successful adoption of e-learning is their motivation [9].

\subsection{Unemployment and employability}

Last decade, high levels of youth unemployment were concerning, a trend exacerbated by recent lockdowns. In the wake of COVID-19's containment measures, came business closures and job losses, with unemployment increasing by 2.9 percent in April 2020 to reach 55 million (8.4\%) [10]. Country differentials are overlaid by gender and demographic variances, with women's work availability declining as their family responsibilities increased during school closures. Younger people were particularly affected, with the unemployment rate of 15 to 24year-olds increasing by 5.5 percent (to 17.6\%) [10]. What are countries doing to prepare youth for future employment?

The pandemic highlighted the economic vulnerability of an over-dependence on international trade, so as business resumes, a 'green' recovery is advocated [11], increasing productivity and cost savings by locally sourced products and reduction of waste [12]. This more sustainable economic model will require new skillsets [13]. Lockdowns have increased unemployment but also highlighted skill-shortages and misalignment of education outputs (graduate competencies) with new industry demands [14]. With high unemployment post-pandemic, there is a 
need for the education sector to focus not just on technical skills, but on the development of employability skills. 'Employability' is the set of knowledge, skills, and attributes that make school leavers and graduates more likely to gain employment and be successful in their chosen occupations. 'Employability Skills for the Future' are communication: teamwork; problem-solving; initiative and enterprise; planning and organizing; self-management; learning; and last but not least, technology [15]. To prepare graduates for an uncertain future, many education providers embed employability into their curricula through work placements and industry cooperative projects. What impact have COVID-19 social-distancing requirements and the introduction of emergency remote learning had on the development of employability skills?

\subsection{Research questions}

This study aims to explore the challenges educators faced during emergency remote learning so that others may learn from their experiences.

The driving question is how was education continuity provided in response to the COVID-19 pandemic in 2020?

Supplementary questions include:

- What steps did countries take to ensure learning continuity?

- How prepared were stakeholders to make the transition to emergency remote learning?

- What were the challenges and benefits that accrued?

- And what can we learn from this experience moving forward, that will better prepare young people for the post-COVID workplace?

To answer these a comparative case study methodology was adopted.

\section{Methodology}

\subsection{Case study}

\subsubsection{Why this approach?}

To gain a useful picture of how the COVID-19 pandemic was affecting the education sector necessitated a different approach from typical studies in teaching and learning. Intermittent $\mathrm{Wi}-\mathrm{Fi}$ access and social distancing requirements precluded online surveys and face-to-face interviews. Despite methodological challenges, the IIIE felt it was important to capture the experiences of ordinary teachers as they grappled with the challenge of maintaining educational continuity. The exploratory nature of this investigation into educators' lived experience of remote emergency learning suggested a case study approach.

Case study is an investigation that answers research questions using the evidence available within a setting. To understand complex phenomena, Stake [16, p. v] recommends making studies of people and operations at different sites. Hence a "quintain" case study approach [16, p. 6], a comparison of three sites within one case was implemented to explore education during the pandemic.

\subsubsection{Selection of the case sites and participants}

In case study, there is a rational selection of one or more instances of the phenomenon. Some case studies illuminate issues through detailed immersion in one case, but a comparative approach [17] is more reliable for global phenomena, especially where the aim is to learn from the experience of others in dealing with common issues [18], as exemplified by the DEIMP project [19]. For the case study of education during the pandemic, countries for which there was little information available in the public domain were targeted. Three countries that had comparable rates of primary enrolments but diverse economic and demographic profiles were selected by applying a modification of Shafer's typology [20]. As shown in Table 1, using a classification system ensures that there is enough variation to provide a meaningful comparison of the phenomenon under study.

As shown in Table 2, Russia had the largest population and Bahrain the smallest, though it was the wealthiest, whereas Iraq was the poorest, with negative economic growth even before the pandemic financial recession hit.

This study was opportunistic in selecting participants, as all three countries had active IIIE networks. This enabled easy access to educators, and by a 'snowball' technique [26], to other reliable participants (twelve in total).

\subsection{Methods}

\subsubsection{Zoom interviews}

The Zoom meeting application was utilized because it was free yet provided a high quality interactive online communication tool. Zoom was frequently used during the pandemic, so most educators were comfortable with it. A Zoom guide was developed 
Table 1

Comparative case studies: Typological framework

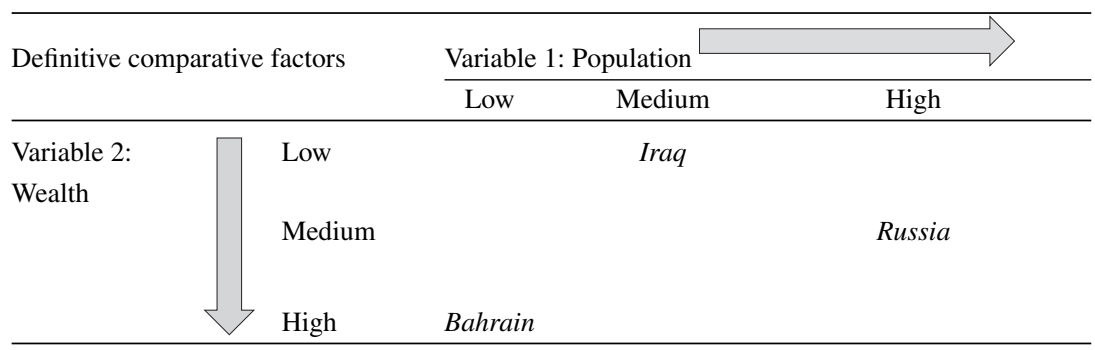

Table 2

Country comparison of key differentiating factors

\begin{tabular}{|c|c|c|c|}
\hline Variable & Bahrain $^{1}$ & Iraq $^{2}$ & Russia $^{3}$ \\
\hline *Net primary enrolment rate & $97.4 \%$ & $93.3 \%$ & $97 \%$ \\
\hline *Lower secondary completion rate & $97.3 \%$ & $48.1 \%$ & $98.9 \%$ \\
\hline *Literacy rate of 15 -24-year olds, both sexes & $94.1 \%$ (data missing). & $52.3 \%$ & $99.7 \%$ \\
\hline Schools (\# students) & $281(189,244)$ & $14,000(\mathrm{M} 4.3)$ & $70,000(\mathrm{M} 20)$ \\
\hline Higher Education (\# students) & $18(27993)$ & $28(240,000)$ & 741 (M4) \\
\hline Population $^{4}$ (urban dwellers) & M1.7 (89\%) & M40 (73\%) & M146 (74\%) \\
\hline GDP/capita ${ }^{4}$ (Rate of change 2017 ) & USD $\$ \$ 23,715(+3.88 \%)$ & USD $\$ 5,114(-2.07 \%)$ & USD $\$ 10,846(+1.55 \%)$ \\
\hline
\end{tabular}

Sources

$*[21]$

1. 2018 data [22]

2. [23].

3. $[24]$

4. Population (24 August 2020) and Gross Domestic Product (GDP) data [25].

with prompts designed to address questions arising from the literature (Appendix A). This 'naturalistic' approach was adopted so group and individual interviews were conversational. With permission sought prior, interviews were recorded unobtrusively using inbuilt Zoom functionality. Some of the Moslem women interviewed did not wish to have their video cameras switched on, but this did not impede the research because analysis could be done using audio recordings without compromising participants' confidentiality.

\subsubsection{Documentary analysis}

Documentation included both hard copy publications, such as journal articles and international reports, as well as 'soft' documents including social media opinion pieces. This wide scoping enabled the views of a range of stakeholders to be collected despite access restrictions due to COVID-19 risks.

\subsection{Analysis and reporting findings}

The in-country investigations and literature reviews were analyzed using a grounded theory approach [27], which allowed for themes to emerge, which were then explored further in an iterative manner using both group and individual Zoom interviews, as shown in Fig. 1.

Based on the emerging themes, selected segments from Zoom interviews were extracted and spliced together to form composite narratives that were enriched by published opinion pieces and reports representing a wider stakeholder view for each country. Each full country profile comprised three sections:

- Statistical data (population, GDP, month by month timeline)

- Composite narratives (Zoom)

- Discussion informed by relevant literature.

A comparative analysis of these full countryprofiles refined the emerging themes into storylines [27]. A condensed 'story' of each country's experience was derived for publication. Member checks [28] ensured the accuracy of these, the overall rigor of interpretation, and the academic content of the case study comparison with its storylines. 


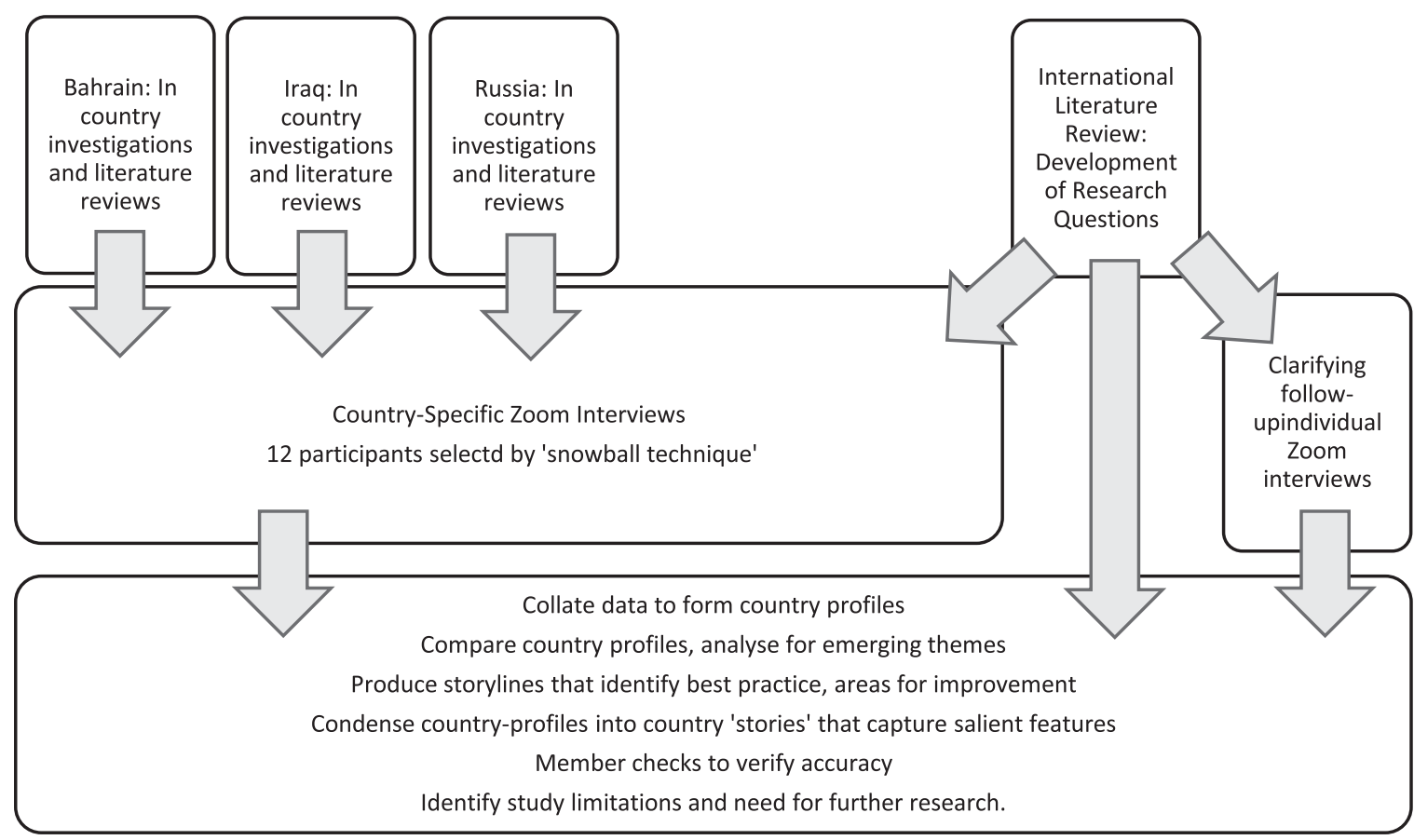

Fig. 1. Research design following selection of comparative cases.

\subsection{Confidentiality}

To preserve confidentiality educators participating are not identified, higher education institutes and schools are unnamed, and the common word 'teacher' applied. Only audio recordings of Zoom sessions were utilized in analysis and, as a further protective measure, slices of narrative (identified by italics) from several different Zoom events, are spliced together to prevent disclosure by association.

\subsection{Reliability and generalizability}

Drawing on the personal experiences of educators from Bahrain, Iraq, and Russia enabled rich stories to be developed within this case study. Storytelling, has the advantage of being able to engage participants within the comfort and security of their own environment [29], hence improving the trustworthiness of findings. It is a "powerful way to exchange and consolidate learning" [30, p. 1].

Whilst it can be argued that case study lacks representativeness, the typically rich stories enable a deeper understanding of the situation than is provided by other methods. Case studies are contextually situated, so what works best in one country, may not be appropriate in another. It will therefore be up to the reader to take from this case study what seems relevant to apply to their organization.

\section{Case study findings}

\subsection{Timeline}

Aggregated school closure data between 21 January and the end of July 2020 [31] established a timeline. This showed the early stages of virus infections, where no measures were put in place (January, February), were followed by official recognition of the spread of infection (early March), with containment measures typically followed by widespread education closures at the height of the pandemic in April. The course of the disease was slightly different for each country, with Iraq seeing the earliest spread of cases, but all suffering second-waves of infection.

\subsection{Context}

To provide an educational context, each country's progress against the United Nation's Sustainable Development targets for quality education in the Sustainable Development Solutions Network (SDSN) report are compared in Table 2 [21]. Participation in primary education was similar, with enrolments 
ranging between 93\% (Iraq) to 97\% for Bahrain and Russia, results above world averages [7]. The SDSN reported progress towards inclusivity and quality targets (SDG 4) was on track for Russia and Bahrain, although the gap in participation levels widened at the secondary level and beyond, especially for Bahrain, with missing data for adult literacy. Iraq progress data for 2019 was unavailable, but Table 2 shows significant challenges in secondary completion and overall adult literacy masking gender inequities noted in other reports [32].

\section{Bahrain}

\subsection{COVID-19 timeline}

In Bahrain, from Feb 24 to 12:48 pm CEST, 23 August 2020, there were 49,038 confirmed cases of COVID-19 with 183 deaths.

\subsection{Bahrain's experience}

\subsubsection{Schools}

"Private schools already had online learning. My kids are there, they record lessons and send to parents and students, with a timetable to attend Zoom lessons. For some working mothers, it wasn't very useful." In government schools: "Each student already had an account and password, so after two weeks of training teachers, online provision started. YouTube was available on day one, but later lessons were offered live on television and Microsoft Stream." Early childhood "provision varied, with booklets, learning tools, and toys sent home to encourage parents as first teachers. Some managed to get training for parents, but daily sessions weren't offered. Some parents refused to pay the fees which centers needed to pay teachers, causing some to close, so it was a mixed response."

The differentiated provision for gifted and talented and students with special education needs was continued online: "The differently-abled struggled more, but specialist teachers gave one-to-one lessons with parents. [Teachers] were more than qualified to design programs and monitor. Each teacher set up classes, with booklets online for students to do their work. The teacher looks at the work and grades it online. 'Stream' is used, has a series of videos made by teachers themselves on how to use. Teachers are helping other teachers."

\subsubsection{Higher Education}

At university (01): "Blackboard had been in place a long time, but not well used by most of the teachers. They uploaded the modules but used it like a curriculum management tool, with few teachers using other features. Ninety percent of the teachers were working from home. It was the way they used to teach, just videoed their lectures, and uploaded online. First 2 weeks, all the teachers were brought to the labs and tried to make videos for all the sessions. Some teachers continued with live classes but for others, it was like learning off the internet. Assessments were done online, but students didn't have the same questions at the same time, and they had limited time, 20 questions, random order, so if a friend sat in, they wouldn't be able to answer. A higher percentage for presentation and discussion was added to the overall judgment."

At university (02) "teachers couldn't work at home, had to go every day, even if not teaching. There is a mistrust of academics, we swipe cards when coming in and leaving, but the allied staff were working at home on alternate weeks-very kind to them -and mothers working from home-not so for academic mothers, we had to come in. People were feeling anxious as at risk. Three staff got [COVID-19], so was this from work?" Lack of clear direction from management exacerbated fears: "Poor decision making, different decisions each day. The level of anxiety was such that:" after the summer holidays many will not return. The negative thing, management assumed it was very easy to move [from] face to face to online. They didn't provide us with much training, it was only your own learning, looking for things online. They sent webinars but they were theories. We wanted something practical. In one week, we had to change all courses into competency."

Even where digital platforms were already wellembedded going fully online was a challenge: "Moodle was already used daily, but still, when it went fully online, we struggled. We were supposed to have a contingency plan, but we didn't. We had IT problems, in that first week it was horrific, we missed a lot of classes due to overload. It became better, but only because some teachers moved to other applications, which took the pressure off. One teacher was just reading the information off-screen. In better classes, students could write on BBB (Moodle's Big Blue Button) and that's how we got interaction. Some classes were recorded in advance, so students did not feel motivated to reconnect in live sessions. Some teachers were better prepared, using asynchronous learning, online quizzes with self-evaluation, and use 
of an application within Moodle that allowed students to do labs in their own time. The teacher spent one to one time with those struggling while good students worked autonomously. Students asked for additional work, so, optional advanced labs were offered." This was close to fully online learning provision, but: "it was already in the plan before the pandemic started."

\subsubsection{Stakeholders}

Students

"Luckily in Bahrain, the percentage of students with good internet and with access to computers at home was high. More where they are doing studies, no space at home and coffee shops closed, but there was little feedback on any problems."

Students' engagement was a concern:

- "Students are from a multi-media generation, they have a mobile, a computer, yet they aren't engaging. The sessions are an hour but need a variety of activities, as in face-to-face. "

- "Students silent, online, but not engaged. Were they asleep?"

- "Can't see students' expressions, they were shy to talk as families around them, so one or two would speak, but others would write things on chat."

- "Missing body language, girls particularly don't open"

- "Connection problems. Using videos made it difficult, it was slower than when used voice alone."

For many students "it was a blank semester. They could withdraw from a course, but few did this. Keen students put more time in, others took life easy. Online learning is only suitable for self-motivated people."

Teachers

Despite the many challenges, teachers thought it had been successful, "when I looked at their assignments, they did well. Despite all the stress, I could see they improved"

"When teachers went online, they forgot everything they knew about learning and good teaching practice, but expectations will be higher going forward, to ensure enjoyment and engagement, teacher and students."

Leadership

Government leaders provided clear support and direction to the education sector: "Parents are concerned, and fearful. At first, they didn't want to stop education, it was a high-level decision to close, so efforts were made to continue with distance learning. Mothers had to work at home to support children's learning. Where the women were doctors and nurses, their partners had this role. The government told parents: 'It's your time now.' Parents said: 'Okay, let's see if we can'. Parents had a hotline to ask questions."

Effective leaders called on the community for support in higher education, where: "Management linked with Batelco so got bigger access to broadband, access was good." Similarly, in schools: "Ninety percent of homes had access to the Internet provided free of charge 7 am-3 pm by private companies. Parents were asked to apply if they needed help. Those families that didn't have computers, some banks, and charities supported them. The whole community got involved".

Although there were occasional stories critical of leaders handling of the pandemic crisis within the Higher Education sector, in general, managers' perceptions were positive about the future: "Now teachers understand the importance of meeting learning outcomes, not getting a grade, to pass. So, a benefit is that this has raised teachers' understanding." This success was based on goodwill, with staff pulling together "making the system work. It's not the silver bullet. There are limitations, not covering all the skills, quality, and learning effectiveness. There is a mismatch of perceptions-students questioning the value for money, and teachers' increased workloads, but it ensured continuity, it was available."

\subsubsection{Quality}

Quality was an issue across the board with "a lot of backlash from teachers," stressed by suddenly dealing with online provision. In schools, the quality of lessons was routinely monitored and if the "electronic lessons were not as should be, they were deleted and redone. The best is put on TV and YouTube, especially in secondary. These are continually updated, a positive aspect for students as they can review." Surveys evaluating the learning experience identified some problems: "Some parents said to get rid of the headaches, they admitted that they did the work. They realized that didn't help their kids learn, whispering the answers to them in the headphone. The Ministry messaged parents, saying it's okay for children to do mistakes, 'Assistance will be given'. Students need to learn how to solve problems, not just memorize. So, one of the benefits was that students gained more responsibility for their learning. The parents now appreciate teachers' role and recognized that tests are not a 'cut point'. Assignments are now given more value. Students appreciate being in class. They value their friends around them." 
Most tertiary institutions adopted noninvasive monitoring "people always there in the background, but the feedback was voluntary, variable" Institutions also used "surveys and selective interviews, but data not available". Results suggested that students "liked it a lot, better than having to travel such a long distance. Some students felt disadvantaged as not enough time, but they liked the choice to sit a deferred exam or do it online. Those wanting fast graduation will have to do the online assessment, but this means double work for teachers. Teachers questioned the changed assessment regime: "is the data reliable? It's too early to say whether students are really learning."

\subsubsection{Pastoral care}

There were concerns voiced about wellbeing:

- "The effects of online education, including eyestrain, mental health, and weight gain."

- "Worried about mental health issues, anxiety is rising. There is uncertainty and suicide."

- "Hectic for parents".

- Huge stress, [as graduates are] "likely not to find a job, so encouraging entrepreneurship".

\subsubsection{The future}

One of the key issues with online learning is the development of "soft-skills—need to find ways for this." There is a need for educational institutions to develop the "competency needed for the new normal, increase employability and prepare students using a new model. So don't measure this by exams. Will look for job skills. Take, for example, attitude. Are they engaged and focused?" Universities encountered problems developing employability skills during the pandemic: "So ironically we were best placed to do this, problem-solving and every course had to have a collaborative group project. Teachers were asked not to do group work; the reason was that the students didn't do a group assessment. Those who had to go to the field did interviews by phone or emails, but a varied response from the industry. Canceling the semester was discussed. A bit of fudging, with students describing rather than building the projects, but next semester will run extra labs to give practical skills, such as using the lathe, welding, but this will only work if we come back with no social distancing, as if we have half the number of students, we will not have enough staffing, and currently we cannot recruit. The use of simulations and virtual reality was considered, but no money." For safety, we "want social distancing, so we need to build this into collaboration on projects. And how to gauge collaboration?"

It was pointed out that this was: "temporary $e$ learning, it's not true e-learning as yet. However, the experience has accelerated the use of online learning. We will be looking at blended in the future, but we needed more ICT help, greater student support, and making it legal for online qualifications".

\subsection{Discussion}

Bahrain's relative wealth and historical investment in education eased the adjustment from face-to-face to distance learning during the pandemic. Private schools and higher education had varying exposure to online learning on which to build, but educators clarified that this experience was an emergency response to provide continuity. Lack of preparedness for the changed direction raised issues of quality, equity, and meeting the changing needs of the labor market. Bahrain's education system had resisted the adoption of e-learning for many years, and this persisted during the pandemic, "they resisted more change in the mindset of how the classes should be delivered and managed" [4].

Social-distancing requirements during the pandemic prevented students from gaining hands-on experience in their field [14], so their education became more theoretical than practical, limiting the development of employability skills and technical competencies. Based on this realization, and the results of a recent study of students' experience and graduate requirements [13], greater use of the 'flipped-classroom' is advocated to better prepare students "for the new normal" [4] by developing the problem-solving and collaboration skills essential in an uncertain labor market.

The Bahrain experience revealed concerns about staff and student well-being during the pandemic. The absence of contingency plans and inadequate IT support raised staff anxieties. In some institutions management of the crisis lacked empathy and clarity. This highlighted the importance of engaging employees effectively through the mediating effect of knowledge sharing for employees of higher educational institutions aiming for optimum organizational performance as the physical workplace is converted into a virtual workplace [33].

With the likelihood of future hybridization of education, Bahrain needs to use the learning from the crisis to develop a more sustainable, user-friendly, approach to online learning. 


\section{Iraq}

\subsection{COVID-19 timeline}

In Iraq, from Feb 24 to 12:48 pm CEST, 23 August 2020 , there were 201,050 confirmed cases of COVID19 with 6,353 deaths.

\subsection{Iraq's experience}

\subsubsection{Schools}

"Pre-pandemic, all governmental schools depended on traditional face to face learning. Some private and international schools used e-learning via google classroom. Otherwise, online learning wasn't used before."

Reasons were:

- Lack of training and experience to "perform this difficult technological mission"

- Many students and teachers did not have e-mail accounts

- Weak or uninterrupted internet in many regions as well as frequent electricity outages

- The curriculum "depends in essence on direct memorization in the presence of an instructor and a receiving student."

\subsubsection{Higher education}

Interactive conferencing applications were used to support virtual lectures: "We give a pdf and a video and a quiz for the next week. We ask for a report from students. Students post questions via WhatsApp, as well as Zoom, Viber, and Telegram. We use whatever the student has, which makes it hard for teachers to accommodate. Students call later if they don't understand, not during it. Attendance and non-participation, teachers follow up. If the problem persists, then the university's administration also follows up. Virtual meetings, conferences, symposia, and workshops allowed collaboration among both Iraqi and international universities, achieving excellent results."

\subsubsection{Stakeholders}

Students

One of the biggest challenges was the "teacher, providing a digital culture for learners. Because we are social creatures, the solitary experience of online learning can be a major hurdle for some students. Teachers attempt to address this through online forums but students' participation in discussions is sluggish. You need to be patient because it may take days for replies to be posted."

Teachers

"Teachers acquired online skills either because they wanted to develop themselves, or because this was the only method of giving lectures. Some younger teachers were eager to take training courses and within two months, they acquired enough expertise to provide excellent lectures to their students. These proactive teachers have already decided to continue with e-learning in the future, within a blended learning system". A few, "who did not have previous experience either rejected e-learning or had little interaction with it."

Teachers were concerned about:

- Lack of official recognition of qualifications obtained from online courses

- Poor Internet connectivity, high cost, and electricity outages

- Lack offacilities and the supportive culture necessary to promote e-learning

- Knowledge of how to use the system.

Leadership

"The National Health Committee issued a decision to close all schools, including kindergartens, since February 2020. Two weeks later, the Ministry of Education issued a decision that teachers should communicate with students electronically through telegram, Instagram, Viber, WhatsApp, and Google Classroom platform. Since 7th March 2020, the National Health Committee issued a decision to close all the universities, both undergraduate and graduate, masters and doctoral, studies. One week later, the Ministry of Higher Education and Scientific Research issued a decision for all Iraq universities to begin online learning using Google Classroom and Moodle. Many online courses and workshops were carried out to train both teachers and students on the use of these platforms, which most did not know before."

\subsubsection{Quality}

Quality systems are in place, with online student evaluations, lesson observations, and bi-weekly feedback to teachers: "Gives individual and group feedback on what needs to be developed."

"During the last two-weeks, online exams were conducted for graduate students using Google Classroom, Edmodo, and Moodle platforms for the first time in Iraq. The system of exams is theoretical and depends on the nature of the paper. Invigilation ensured authenticity previously: "But now its 
online, students may share answers. It's difficult to change the format to more problem-solving questions. Students find these 'indirect' questions difficult to do online. Institutes reverted to direct questions to encourage students to complete exams. Many students have COVID-19 infections, and the government wants the students to not lose the year, which may cause certain problems in recognizing Iraqi certificates worldwide. So, we need to share ideas on how to get around these problems."

\subsubsection{Pastoral care}

Pastoral care is provided: "Students are worried about their study, but also health issues and their families. Teachers see it as their duty to help students, to encourage them."

\subsubsection{The future}

"In most Iraqi institutions online learning had many benefits, including the ability to complete the curriculum and not miss the academic year, especially for the students about to graduate". As a result of the positive experience during the pandemic, it is expected that authorities will encourage universities to "accept online education as part of the teaching and learning processes in addition to the face to face learning, and this, in turn, will lead to staff having to consider which part of the educational curriculum will be presented through classroom lectures and any part that will be presented online. This will happen despite the opposition of many students to online education, despite the weakness of teachers' knowledge of its methods, and their lack of experience. e-learning has been recognized as less capital intensive and improves students' digital proficiency. Virtual education may revolutionize higher education because today's students have a higher ability to adapt to technology and electronic portals".

Traditional teachers, set in their ways, pose the biggest challenge: "I expect they will not continue with e-learning due to little experience and lack of interest. Iraq will face challenges in merging these teachers into a future blended system." Other barriers are the "intensity of the curricula and systems that preclude the rapid development of programs, the lack of available infrastructure, slow communication network, and insufficient equipment. A further challenge is how to enable students to meet the practical requirements for professional qualifications in the applied sciences, whilst studying online."

\subsection{Discussion}

Iraq's historic challenges, with children and adolescents missing out on formal education due to conflict and shortages of qualified teachers have been exacerbated by the advent of COVID-19, but this was not mentioned in the Zoom interviews. That access to education is limited by movement restrictions and availability of civil documentation required to facilitate enrolment is, however, well-documented [32], with 1.4 million people $(658,000$ children) internally displaced, mainly in the north and west. There are 14,000 registered primary schools in Iraq, but only 11,368 buildings available to house the 4.3 million primary-aged children, so shifts are run, reducing classroom time (especially for Kurdish children [34]). To support equity of access, Iraq had gained international funding for the digitalization of learning across both schools and in higher education. While the internet is available in five percent of homes, and 80 percent of the population owns a mobile phone [35], 88 percent can access a television set, so broadcasts of learning and health promotion in Arabic, Kurdish (Sorani), and Syriac languages were the main way of supporting learning continuity during the pandemic [36]. Electricity supply is intermittent in some areas, affecting all forms of e-learning provision.

As shown in Table 2, many Iraqi children do not complete high school [21, 23, 37], posing a barrier to continuing education. Supported by the United Nations Educational Scientific and Cultural Organization and Iraq's Ministry of Higher Education, a virtual campus project was launched to integrate e-learning systems within higher education in 2015. Implemented in Basrah and Salahaddin universities, this e-learning pilot used virtual lectures and Google Classroom to support post-graduate students [38] and was so successful that training for online learning was extended to all university teachers mid-2019. Students recognized the benefits of e-learning for their studies but had concerns about the level of support and infrastructure [39]. During the pandemic, students were frustrated by their inability to instantly ask questions, to confer with classmates, and to engage actively in discussions, making for a static experience [40]. They lacked a quiet study environment at home, a modern laptop, and working internet. Anxiety levels during the pandemic meant that it was harder than usual for students to focus and remain disciplined [40].

In conclusion, the clear leadership directives that built on existing foundations of remote education pro- 
vision, coupled with previous training of teachers in higher education and international funding support, enabled learning continuity in Iraq, despite the many historic challenges that the country faced. Lessons that Iraq's education community has learned from this crisis include the:

- importance of up-to-date technology and online platforms as adjuncts to learning

- value of community, international mobility, and partnerships

- role of the environment in students' learning experience.

The use of television and m-Learning widened opportunities for students to continue to learn, so as a result of the pandemic, the adoption of e-learning has been accelerated in Iraq.

\section{Russia}

\subsection{COVID-19 timeline}

In the Russian Federation, from Jan 31 to 12:48 pm CEST, 23 August 2020, there were 956,749 confirmed cases of COVID-19 with 16,383 deaths.

\subsection{Russia's experience}

\subsubsection{School and higher education sectors}

"Schools and universities were closed to face-toface tuition from $30^{\text {th }}$ March, with requirements for 1.5-meter social distancing and wearing ofmasks and gloves within the community to reduce the spread of infection. There were no limits on meeting numbers, but education had moved online, so recruitment for new students was via the web, and doctoral candidates' preparations for online thesis dissertations were conducted by phone. For several years we had an electronic education zone-there had been some work done, a range of applications, using ZOOM, webinar, Microsoft Teams. Teachers were partially prepared, as [e-learning] had been a trend. But the issues for teachers were rapid changes and speed of the changes."

Equity of access: There is "a good situation in Russia for internet coverage. But family incomes vary, so students don't all have the same access to sophisticated software. The university provides computers for both staff and students to make sure all have access. But they don't always have the competencies.
"The public is used to big [COVID] numbers, to being at home, but we are social animals. Online communications don't allow for subtle messages via body language. Online learning is not as engaging, this is a big problem."

\subsubsection{Stakeholders}

\section{Students}

Students' "levels of participation are just as high, but are they engaged? Attendance is high because there is surveillance, but I can see students are drinking coffee, distracted by their cat. Students need to show their faces, where were they? Some were trying to do their finals in the car, and could not print anything, so this lack of focus, concentrating on the topics, is an issue. Self-discipline is an issue." Mature female students have been especially impacted by the move to online learning. In the past, they provided "social modeling that helped [younger] learners, but now it's an issue, they have childcare issues."

Another issue that the students encounter is adapting to each teacher's approach and their technology preferences, which ranged from Blackboard CT, MS teams, Zoom, WhatsApp, and Messenger, to YouTube: "this is a problem in one way, but it helps them prepare for a digital workplace of the future." Students were "using their own gadgets, but the university was available to support them learning online".

While students recognized that the "digitalization of education [is] inevitable," they voiced concerns about the loss of social connections. In a petition to the government presented by High School of Economics students [unpublished data], they bemoaned the opportunity for "live dialogue... .a dialogue between teacher and student and between the students themselves," which they said was missing from online provision during the pandemic. Although Zoom meetings were scheduled, students said technical issues limited effectiveness: "sound disappears, noise appears, image quality is low". The videoconferences "do not allow teachers to track audience reactions [facial expressions]. Thus, during the class, the teacher does not know whether the students understand the material or not, whether they have questions or objections, whether he should dwell on some issue for a longer time or continue the analysis of the material further." A quiet space to study was also a problem, especially for students sharing dormitories, but also for those living at home, as was access to devices suitable for online learning: "some [students] have old, slow-working computers, 
a bad webcam, broken headphones, poor internet. And these students do not have the financial ability to purchase high-quality equipment that will work without interruption during classes." The effects of online study on health were concerning, with claims that poor sound and image quality contribute to an overall deterioration in well-being. Students said that the "need to spend most of the time on the computer screen has a detrimental effect on eye health ... your ears and head start to ache, so performance is significantly reduced for the rest of the day." They were also worried about mental health: "the general psychological state of students after online classes turns out to be quite negative." A further concern that added to students' anxieties was the protection of personal data: "video lectures and seminars can be recorded and then posted on various online resources, various information from both students and teachers can leak." They were also concerned that some vital skills, such as thinking skills, were "not transmitted in the online format".

Teachers

Russian teachers found case studies and group projects were less effective in distance mode. Opportunities for interaction and sharing social experience were constrained by online learning: "Traditional methods of teaching posed constraints on the pace of adaptation to meet the new requirements. Urgent demands to rewrite the curriculum and adopt innovative teaching techniques were made. Teachers needed to rapidly upskill at the same time as redeveloping their programs for use online, leading to high levels of anxiety". Added to this were concerns about the confidentiality of personal data and a lack of technical and financial support available.

"Students send in questions by chats [but] how to be flexible and responsive is challenging, requiring multi-tasking, especially for very traditional teachers who have been doing this for a long time, they needed new competencies." Other issues for teachers were: "new gadgets, old computers, and Wi-Fi capacity" which required an investment in time, as well as money.

Leadership

A lot of problems were encountered organizationally, mostly associated with digitalization demands and technical issues including a mismatch of equipment and software used by students and their remote teachers and access to a high-speed internet connection. "Administrators faced growing volumes of paperwork, with increased monitoring and control requirements."

\subsubsection{Quality}

Quality systems were in place, checking online delivery: "Administration is monitoring, randomly, then sends some notes to head of faculty" for follow-up with their staff. The administration is also monitoring student participation rates and "the teacher gets a warning if the students are not visible."

There are robust systems to engage students and ensure the authenticity of their work, with each student having an ID for assessments online: "Its possible students can cheat, but since the final test is no more than 45 minutes, the time is limited", with practical and theory questions reducing students' ability to do a copy-paste: "the practical part is more used in assessments. In the Zoom meetings, you get to see students' performance. The final assessment is individual and private. The communications needed to cheat steal time, so this is a deterrent."

Some universities use artificial intelligence: "A system watches to see if students are searching online and can listen to sounds around the assessment." Universities are not able to change results because of surveillance evidence, but it can be used to curtail students' life in other ways, such as recommendations for internships.

\subsubsection{Pastoral care}

Teachers use chats to support the students: "The teachers are like a father, reminding [students] what links to put in, as too much information plus a lot of stress".

There is a 'Hotline' both students and staff can call if they have any issues, such as feeling anxious, and this is promoted when running online courses. There is also a direct line to the university rector, "so students can complain, or even if good, this is followed up. Students are becoming like consumers. They have a lot of support, teachers trying to be like a parent. We can understand them feeling anxious and respond."

\subsubsection{The future}

A special department deals with students' future careers, arranging internships. Alumni help secure jobs, but today: "Students are upset and depressed. Their plans to go to post-grad European schools put on hold. A lot of companies are closing, so where will they work? Many had been planning to study abroad. Now they will stay in Russia-so the market might be bigger [for private schools]. The competition by these mobile students will push up achievement in government schools. The government universities have high 
standards, but maybe less flexible" in responding to changed workforce requirements.

Russia's education response during the pandemic "will lead to new conditions; it's a trigger for changing the mindset. Our students are changing, but they are afraid, afraid of changes; they are worried that online will not deliver preparedness for jobs."

\subsection{Discussion}

The blended approach to learning already being promoted across the Russian education sector was accelerated by the pandemic. This story was not well-differentiated by sector but illustrated-well two different perceptions of emergency remote learning, students, and academics. The organizing of online connection and establishment of systems to monitor students' class presence and attendance appeared relatively straightforward, given the clear leadership directives during the pandemic, and prior experience beforehand, but the lack of student engagement and group participation remains a challenge. Members of the learning communities exhibited varying degrees of stress about online learning and anxiety about the pandemic.

Perepelkin and Guseynova maintain that the need for professional skills, and active interaction in the virtual space and electronic environment, is dictated by the rapidly changing requirements for the training of specialists and their awareness of this problem, as well as new occupational and social communication requirements [41]. Technical skills, as well as 'employability skills' are needed to meet the demands of today's changing world. The use of short courses to upskill competencies, supported by longer e-learning programs, form an effective strategy to meet changing requirements [42]. Consequently, e-learning has become a distinctive feature of education development in Russia, informed by global trends in information and telecommunication technologies. This change revolutionized the educational process, forming a global environment for intercultural and interdisciplinary integration that has paved the way for life-long learning, a necessity given today's knowledge economy. This transformation opens a new set of challenges: organizational, cognitional, and psychosocial. The organizational aspects have already been touched on, but the other dimensions are elaborated below.

From his experience during the pandemic, Perepelkin's [unpublished data] analysis of cognitional aspects indicated the need for a more effective, model of knowledge acquisition for use in remote education. He argues that information is acquired differently through digital sources, partly attributable to age segmentation (older people prefer hard-copy), but also to concentration times, which he found differed in online and offline events-remote and internet communications take longer to prompt a response.

Psychosocial aspects he identified included the need for success in studying, provision of a stimulating level of competition, and the possibilities of collaboration. With the disruption to daily routines, Russian students demonstrated a lack of self-discipline and poor time management, struggling to concentrate on study tasks. Their communication and interpersonal skills need to be developed in 'live-action', not simulations, with the possibilities of learning from each other being 'priceless', Perepelkin argues,

Post-pandemic, a new model of education is required to address the concerns identified about the educational process and its management. This model needs to build on the benefits online learning brings, especially access for mature working students and learning anywhere, anytime, whilst addressing concerns for health and security and promoting innovative teaching and engaging learning.

\section{Comparative storylines}

Congruent with a six-country comparative study of "Education in Precarious Times" [19], this study found that education continuity was provided for during the pandemic using a mix of remote learning modes that reflected the course of the disease and each country's unique geographic, economic, social, and political factors. These same factors also impacted the quality and inclusiveness of the remote emergency learning strategies employed, with Iraq particularly disadvantaged by a history of "neglect and war" [37].

The DEIMP project found some institutions had "neither the resources nor the inclination to support online and distance learning at this quality and scale and most seem to have implored their staff to convert their existing face to face provision into distance learning within a few weeks, with little or no formal training and support" [19], a story that resonated with educators' 'lived-experiences' reported from Bahrain, Iraq, and Russia. Despite problems 
largely associated with inadequate implementation time, it was apparent in all nine countries (six in the DEIMP project and three in this case study) that the spread of COVID-19 accelerated trends previously evident in the education sector, such as the use of technology in teaching and assessment of learning. Both studies emphasize the need to build on what has been achieved during these unprecedented times to ensure more equitable access in a future sector predicated by hybrid-delivery. Whilst confirming the DEIMP recommendations and those of Buheji and Ahmed [4], that encompass strategies for more effective remote teaching and learning, this comparative case study additionally endorsed the need to re-evaluate how the changing needs of the economy for work-ready graduates can be met [13-15]. Further, from Russia's experience during the pandemic, Perepelkin [unpublished data] argues for a more effective model of knowledge acquisition for use in remote education, on the basis that information is acquired differently through digital sources.

That emergency remote learning differs from online learning utilized in a blended environment is a point also made by Hodges et al. [3]. As the physical workplace converted into a virtual workplace during this crisis, it posed challenges for the adaptability and flexibility of managers who found it difficult to share information and motivate their teams remotely [33]. The importance of clear and empathetic leadership in navigating through a crisis with optimal organizational performance was highlighted in this case study.

Stories can provide compelling forces for social change, [18, 30], and whilst this study concludes that COVID-19 accelerated pre-existing trends, its exploratory nature also highlighted best practices and areas for improvement as education moves towards a more blended future. In the concluding section, a more 'fit-for-purpose', inclusive form of hybrid learning closely linked with parallel economic and employment changes is proposed.

\section{Conclusion}

Case studies are contextually situated, so what works in one country, may not be appropriate in another. Whilst it is therefore up to the reader to take from this case study what seems relevant to apply to their own situation, implications for practice are canvassed and areas for future investigation identified.

\subsection{Implications for practice}

Each country had previously invested in distance and e-learning, so built on this foundation during the lockdown period to provide learning continuity. Despite issues such as electricity supply, Wi-Fi strength, and access to equipment, most providers ensured continuity through a mix of distance and online learning delivered by committed staff. The importance of clear and empathetic leadership in harnessing the human factor (motivating both staff and students [9, 43]) during the stress of the crisis was one of the key learnings from this case study.

Both synchronous and asynchronous strategies were implemented, with online learning and television the most common media, depending on access to technology. Learning provision ranged from traditional sessions (with teachers simply videoing a lecture and students completing questions) to more interactive sessions that reflected best practice, with online class discussions, group collaborative activities, and individual presentations [4, 19]. This study demonstrated that delivery quality was improved by efficient IT services, timely training, and collegial networking that promoted the use of e-learning and developed a supportive culture. An area warranting further attention in planning on-line lessons is student engagement. This posed one of the biggest challenges, with female students particularly reluctant to be seen online in Arab countries.

Educators were aware of students' feelings of isolation and the difficulties that they experienced in learning remotely. A highlight was the consistent evidence of educators' care and responsiveness, with community provision of equipment, multiple delivery modes, and, in the case of Bahrain, special programs for gifted students and those with identified learning needs. Whilst technology can be used very effectively to identify, monitor, and respond to the diversity of learning needs, the potential widening of the performance gap between higher-achieving learners and their peers was a concern voiced. Whilst students' stories about their experience were limited to secondary sources, except in Russia, the anytime/anywhere benefits of asynchronous learning already known to working students may provide learners who were not succeeding in the face-toface system the opportunity to succeed by allowing them to work at their own pace. This benefit of remote learning provides a clear pathway for developmentally delayed or disadvantaged learners to optimise their performance, potentially reducing any 
achievement gap with peers. Monitoring to ensure continuous academic progress for the diversity of learners, as well as more effective systems for the pastoral care of remote learners, are aspects that require greater attention by the sector in moving e-learning forward.

For those students able to access online learning, they will likely have gained a better understanding of the ethical use of technology, as well as becoming more self-directed as learners. Such skills will better prepare these young people for the new way of working in the changing business world, an emerging conclusion that needs verification. However, the development of practical skills that the workplace also requires was not well-catered for in online education. Rarely were industry projects and laboratories incorporated into remote emergency learning during the pandemic. The use of simulations, virtual reality, problem-solving using industry problems, and other best-practice work-integrated-learning strategies were seldom reported. As businesses set to reopen, many governments are calling for a green recovery, with a greater focus on sustainable practices, recycling, and environmental awareness. This change flags a major implication for the education sector, necessitating urgent curriculum review to ensure the continued relevance of programs in the 'new normal'. With rising unemployment postpandemic, the curriculum needs to include a greater focus on sustainability, as well as the development of students' enterprise, innovation, and entrepreneurship skills.

The education sector was not well-setup to offer dedicated online and remote learning. What was hurriedly put in place was an emergency response to ensure continuity in a crisis. Consequently, academic staff felt unprepared and under-resourced. Many had been using applications such as Moodle, Blackboard, and Google Classrooms before, but being fully reliant on these applications to deliver engaging learning experiences was quite a different situation and very challenging. Any crisis needs clear direction and empathetic leadership to avoid the kind of stakeholder disenfranchisement this case study reveals may have occurred with both students and staff, in some institutions. An unanticipated benefit of leaders' lack of contingency planning was an increased level of social networking amongst academic staff, as they grappled to solve common problems facing the sector. This best-practice collaboration developed a greater awareness of e-learning pedagogy and with it an interdisciplinary understanding that might, in turn, be reflected in more innovative teaching programs in the future.

This case study, congruent with the findings of others $[13,14]$ indicates that education post-pandemic will slowly readjust to a new reality which, through building on the lessons learned during the period of emergency remote learning, will facilitate a more effective blended approach. Issues requiring consideration to achieve educational quality and greater inclusivity will be enhanced responsiveness to the learning needs of a diversity of students, new ways of regulating quality, especially the credibility of assessments, and more effective pastoral care for students and staff who feel anxious and isolated when programs run remotely. The concept of quality in education is a fit-for-purpose system that produces work-ready graduates, able to take a positive role as citizens in the wider society. Educational quality is therefore closely linked with parallel economic and social changes, so the development of twenty-first-century skills remains a key focus in both schools and universities. Specific issues, such as how practical skills can best be developed and assessed online, will require particular consideration.

\subsection{Recommendations for further research}

In summary, this case study provided a useful exploration of the challenges facing the education sector, which can be seen to fall into three main categories: crisis management and decision making, infrastructure readiness, and student receptiveness. But whether the three countries that make up the case study are representative of the international community's experience is open to question. Like many country-wide comparative case studies, this unstructured qualitative research can be critiqued for its "generality and explanatory imprecision" [20]. Further, more quantitative studies are recommended to assess the depth and extent of the impact of the pandemic on education, how it affected teachers and teaching, how it affected learners and learning, and how the role of schools and universities needs to change to better prepare young people for the 'new normal'.

While ensuring equity of access in smaller countries, such as Bahrain, was relatively easy given the structures already in place, in Iraq, beset by conflict, poverty, and geographic spread, the situation was much more challenging. Indeed, e-learning has faced many unique challenges in Arab and develop- 
ing countries, some of which software companies can help to address. Language barriers exacerbate learning difficulties and, recognizing this, some software designers have improved learning efficacy by producing Arabic versions of the software. By adapting platforms for mobile phones, with their anytime/anyplace advantages, they improved access to learning [43]. Further studies are recommended to investigate the extent and nature of e-learning in Arab and developing countries to facilitate further collaboration with industry for mutual benefit.

Despite such initiatives, UNICEF claims that inherent inequalities in access to tools and technology during the COVID-19 pandemic have deepened the global learning crisis [5]. Educators' stories showed awareness of inequities but also evidenced proactive community support to redress access and equipment issues. How effective these strategies have been, and how widespread, requires further investigation. Whether the challenges facing children and young people, as they grapple with the realities of remote learning, have resulted in higher drop-out rates, for example, requires access to quantitative data not available at the time of this study.

And last, but not least, it is recommended that governments focus on the viability of education institutions in the post-COVID recession. Given the funding and staffing shortages predicted, without additional support, some may fail to make the rapid adjustments needed to become effective 'hybrid' institutions that offer a more blended learning approach.

One cannot help but be amazed, humbled, but at the same time also proud, of the dedication shown by educators in this case study. Despite very different circumstances, very different education systems, highly variable levels of preparedness, and inadequate resourcing for remote learning, they did their very best to ensure learning continuity in a time of crisis. They had to work very hard to develop new skills, new resources, and new programs, to support learners' survival and growth in these challenging times. An outcome is the revaluing of social relations in teaching and learning. And parents have a new-found respect for teachers!

\section{Acknowledgments}

The authors appreciate the support from educators in Bahrain, Iraq, and Russia, who willingly gave of their time to participate in this study during the very stressful period during which the COVID-19 coronavirus spread across the globe. Some participants, who wish to remain anonymous, provided information during Zoom meetings, and also contributed newspaper and other articles that reflected public perceptions at that time.

\section{Author contributions}

CONCEPTION: Mohamed Buheji, Chris Coutts, Dunya Ahmed and Talal Abdulkareem

METHODOLOGY: Chris Coutts

DATA COLLECTION: In-country investigations and literature reviews: Bahrain - Mohamed Buheji, Dunya Ahmed and Budhoor Buheji; Iraq - Talal Abdulkareem and Sajeda Eidan; Russia - Nikolay Perepelkin. Zoom interviews conducted by Chris Coutts.

PREPARATION OF THE MANUSCRIPT: Chris Coutts

REVISION FOR IMPORTANT INTELLECTUAL CONTENT: Chris Coutts

SUPERVISION: Mohamed Buheji.

\section{References}

[1] World Health Organisation, "Coronavirus disease 2019 (COVID-19) Situation Report - 51,” 11 March 2020(a). [Online]. Available: https://www.who.int/docs/default-sou rce/coronaviruse/situation-reports/20200311-sitrep-51covid-19.pdf?sfvrsn=1ba62e57_10. [Accessed 13 June 2020].

[2] World Bank, "COVID-19 (Coronavirus) Response," 2020. [Online]. Available: https://www.worldbank.org/en/topic/ education/coronavirus.

[3] Hodges C, Moore S, Lockee B, Trust T, Bond AM. The Difference Between Emergency Remote Teaching and Online Learning, 27 March 2020. [Online]. Available: https://er.educause.edu/articles/2020/3/the-differencebetween-emergency-remote-teaching-and-online-learning. [Accessed 4 October 2020].

[4] Buheji M, Ahmed D. Implications of Zoom and Similar Apps on 'Flip-class' Outcome in the New Normal, International Journal of Learning and Development. 2020; 10(3):1-11.

[5] Thompson G. Unequal Access to Remote Schooling Amid COVID-19 Threatens to Deepen Global Learning Crisis, 4 June 2020. [Online]. Available: https://www.unicef. org/press-releases/unequal-access-remote-schooling-amidcovid-19-threatens-deepen-global-learning. [Accessed 3 August 2020].

[6] United Nations Development Programme, Goal 4: Quality Education, 2020. [Online]. Available: https://www.undp. org/content/undp/en/home/sustainable-development-goals/ goal-4-quality-education.html. [Accessed 3 August 2020]. 
[7] United Nations, Ensure Inclusive and Equitable Quality Education and Promote Lifelong Learning Opportunities for All, 2020 (a). [Online]. Available: https://sdgs.un.org/goals/goal4. [Accessed 27 July 2020].

[8] Symonds Q. How COVID-19 is Impacting Prospective International Students at Different Study Levels, 2020. [Online]. Available: https://www.iom.int/sites/default/files/ documents/covid-19_analytical_snapshot_39_-_internation al_students.pdf. [Accessed 24 August 2020].

[9] Chanchary F, Islam S. Is Saudi Arabia Ready for e-Learning? A Case Study, Najran, 2011.

[10] OECD, Unemployment Rates, OECD - Updated: June 2020, June 2020. [Online]. Available: http://www.oecd.org/ newsroom/unemployment-rates-oecd-update-june2020.htm. [Accessed 22 August 2020].

[11] Mace M, 'Normal Was a Crisis': Why the Green New Deal is the Perfect Response for the Post-Covid19 Economy, 1 April 2020. [Online]. Available: https://www.edie.net/library/-Normal-was-a-crisis-Whythe-Green-New-Deal-offers-hope-to-the-post-Covid-19economy/6971. [Accessed 10 June 2020].

[12] Buheji M, Vovk Korže A, Eidan S, Abdulkareem T, Perepelkin N, Mavric B, Preis J, Bartula M, Ahmed D, Buheji A, Chetiayein T, Beka G, Kakoty P, Das R. Optimising Pandemic Response Through Self-Sufficiency - A Review Paper. American Journal of Economics. 2020;10(5): 277-83.

[13] Ahmed D, Buheji M, Almutawwaa W. The 'Silver-Lining' of Youth Future in the New Normal: Describing a New Generation. Human Systems Management. 2020;30(4).

[14] Buheji M, Buheji A. Planning Competency in the New Normal- Employability Competency in Post- COVID-19 Pandemic. International Journal of Human Resource Studies. 2020;10(2):237-51.

[15] DEST, Employability Skills for the Future, Canberra, 2002.

[16] Stake R. Multiple Case Study Analysis, New York: Guilford Press, 2006.

[17] Bartlett L, Vavrus F. Comparative Case Studies, Educação \& Realidade. 2017;42(3).

[18] Abdulrahman YM, Paulley FG. Studies in Comparative Education: Issues, Processes and Engagements, in Integrated Foundations of Education, vol. 2, Adeyinka A, Osuji E, Asuka T, Orubu A, A. Agih and Ozurumba C, Eds., University of Port Harcourt Press, 2014, pp. 133-167.

[19] Hally T, Connolly C, Grádaigh SÓ, Burden K, Matthew K, Schuck S, Bottema J, Cazemier G, Hustinx W, Evens M, Koenraad T, Makridou E, Kosmas P. Education in Precarious Times: A Comparative Study Across Six Countries to Identify Design Priorities for Mobile Learning in a Pandemic, Information and Learning Sciences. vol. In publication, pp. 1-10, 2020.

[20] Shaffer P. Typology Construction for Comparative Country Case Study Analysis of Patterns of Growth, 2 September 2020. [Online]. Available: https://www.researchgate. net/publication/344045337. [Accessed 8 October 2020].

[21] Sachs J, chmidt-Traub G, Kroll C, afortune G, Fuller G. Sustainable Development Report 2019, Bertelsmann Stiftung and Sustainable Development Solutions Network (SDSN), New York, 2019.
[22] Ministry of Education, Statistics, 2020. [Online]. Available: https://www.moe.gov.bh/statistics.aspx. [Accessed 31 August 2020].

[23] Al-Shaikhly S, Cui J. Education in Iraq, 17 October 2017. [Online]. Available: https://wenr.wes.org/2017/ 10/education-in-iraq. [Accessed 24 August 2020].

[24] Ministry of Science and Higher Education, Study in Russia, 2020. [Online]. Available: https://studyinrussia/en/whyrussia/russian-education-in-figures. [Accessed 25 August 2020].

[25] Worldometers, World Population by Country, 24 August 2020. [Online]. Available: www.worldometers.info/worldpopulation/population-by-country. [Accessed 24 August 2020].

[26] Shakir M. The Selection of Case Studies: Strategies and their Applications to IS, Research Letters Institute of Information and Mathematical Sciences. 2002;3:191-8.

[27] Chun Tie Y, Birks M, Francis K. Grounded Theory Research: A Design Framework for Novice Researchers, Sage Open Medicine, vol. 7, 2 January 2019.

[28] Birt L, Scott S, Cavers D, Campbell C, Walter F. Member Checking: A Tool to Enhance Trustworthiness or Merely a Nod to Validation? Qualitative Health Research. 2016;26(13):1802-11.

[29] Buheji M. Socio-Economic Issues Storytelling for Closing Intergenerational Gap. Journal of Social Science Studies. 2020;7(1):76-87.

[30] Prasetyo YE. From Storytelling to Social Change: The Power of Story in the Community Building, Community Development Academy, vol. III, no. Fall, January 2017.

[31] Hale T, Webster S, Petherick A, Phillips T, Kira B. Oxford COVID-19 Government Response Tracker, 28 July 2020. [Online]. Available: https://www.bsg.ox.ac.uk/research/ research-projects/oxford-covid-19-government-responsetracker. [Accessed 29 July 2020].

[32] UNICEF, In Ninewa, UN Partners Renew their Commitment to Promote Inclusive and Equitable Access to Education for all Children in Iraq, 26 January 2020 (a). [Online]. Available: https://www.unicef.org/iraq/pressreleases/ninewa-un-partners-renew-their-commitmentpromote-inclusive-and-equitable-access. [Accessed 26 August 2020].

[33] Ahmeda T, Khanb MS, Thitivesab D, Siraphatthadab Y, Phumdara T. Impact of Employees Engagement and Knowledge Sharing on Organizational Performance: Study of HR Challenges in COVID-19 Pandemic, Human Systems Management, vol. In publication, pp. 1-15, January 2020.

[34] The World Weekly, The Education Crisis Facing Iraqi Kurdistan, 1 April 2016. [Online]. Available: https://www.theworldweekly.com/reader/view/15889/theeducation-crisis-facing-iraqi-kurdistan. [Accessed 27 August 2020].

[35] OpenNet, 10 August 2009. [Online]. Available: https://open net.net/research/profiles/iraq. [Accessed 27 August 2020].

[36] UNICEF, New TV Education Channel Will Support 1.5 million Learners in Iraqi Kurdistan, 5 May 2020 (b). [Online]. Available: https://ekurd.net/new-tv-educationchannel-2020-05-05. [Accessed 27 August 2020]. 
[37] UNICEF, Iraq's Schools Suffering From Neglect and War, 15 October 2004. [Online]. Available: www.unicef.org/media/media_23630.html. [Accessed 24 August 2020].

[38] N. Ameen and Willis R, An Investigation of the Adoption of Educational Technology in Iraqi Higher Education: Evidence from Salahaddin University, in UKAIS Conference Proceedings, 2016.

[39] Ameen N, R. Willis and Abdullah MN, The Use of eLearning by Students in Iraqi Universities: Potential and Challenges, in 8th International Visible Conference on Educational Studies \& Applied Linguistics, Iraq, 2017.

[40] Feller R, COVID-19 is Transforming Education for All: Fast Tracking the Shift to Distant Learning, 20 June 2020. [Online]. Available: https://www.atlanticcouncil. org/blogs/new-atlanticist/covid-19-is-transformingeducation-for-all-fast-tracking-the-shift-to-distantlearning/. [Accessed 30 August 2020].
[41] Perepelkin N, Guseynova Z. Elektronnoe Obuchenie Kak Sostavlyayushchaya Innovatsionnogo Razvitiya i Konkurentosposobnosti Vuza, in Sovremennaya Ekonomika: Kontseptsii i Modeli Innovatsionnogo Razvitiya, Moscow, 2018.

[42] Lukina NA, Skorobogatykh AV, Perepelkin II, Kartashova LV, Ivashkova NI, Musatova ZB, Tsvetkova AB, Tultayev TA, Malova DV, Kuznetsov VV. Razrabotka Strategii Prodvizheniya Dopolnitelnykh Obrazovatelnykh Pprogramm Universiteta. Plekhanovskiy Nauchnyy Byulleten. 2018;1(13):50-55.

[43] Ali MI, Ghazi AB. The Effect of Using Google classroom on the Achievement of Computer Department Students in Image Processing Subject and their Attitudes Toward eLearning. International Journal of Research in Educational Sciences. 2019;2(2). 


\section{Appendix A: Country Profile Zoom Guide}

Country name:

Interview date and time, participants, and role(s)

Introduction: (confidentiality, recording)

Situation today in named country (extent of infection and strategies to contain it)?

Situation today regarding education? Situation prepandemic?

- Schools

- HE

Predictions for trends post-pandemic?

- Blended learning?

- Employability skills?

- Changing world of work?
Issues and concerns?

- Use of technology in teaching-how do teachers feel? Preparedness?

- Students' experience?

- Assessment issues?

- Quality issues?

- Equity-access issues?

Data status-reliable? Engagement? Participation? Drop-out?

Recommendations?

Further research? 